\title{
A Fault Management Oriented Early-Design Framework for Electrical Propulsion Aircraft
}

\author{
Marie-Claire Flynn, Catherine Jones, Patrick J. Norman, Graeme M. Burt
}

\begin{abstract}
Electrical propulsion has been identified as a key enabler of greener, quieter, more efficient aircraft. However, electrical propulsion aircraft will need to demonstrate a level of safety and reliability at least equal to current aircraft to be a viable alternative. Therefore, a robust and reliable fault management system is needed to prevent electrical faults causing loss of propulsion and critical flight functions. To date, fault management of the electrical propulsion system has not been considered in detail for future electrical propulsion aircraft, nor has it been effectively integrated into the electrical architecture design. This poses a risk that the proposed electrical architectures will be infeasible from a fault management perspective, and key fault management technologies may not be sufficiently developed. Therefore, a methodology to incorporate fault management into the early stages of design of electrical architectures is required to determine viable fault management solutions for a given electrical propulsion aircraft concept. This paper describes a novel, systems-level electrical architecture design framework for electrical propulsion aircraft which incorporates fault management from the outset. This methodology captures the significant assumptions in the design and acknowledges the novel interfaces which exist between the electrical, conceptual and fault management design of electrical propulsion aircraft.
\end{abstract}

Index Terms—fault management, electrical propulsion aircraft, electrical architecture, protection

\section{INTRODUCTION}

$\mathrm{E}$ LECTRICAL propulsion has been presented as a possible solution to reduce aircraft noise and emissions, and to offset the environmental impact of a continued 5\% annual increase in global levels of air travel [1]. Focus so far has been given to the development of aircraft conceptual designs and underpinning electrical technologies with the capacity to meet the ambitious performance targets set by NASA [2] and the EU [1]. To date, performance road maps for the development of electrical machines, power converters, cables and energy storage have been proposed as it is clear that the viability of future aircraft electrical propulsion will depend largely on these technologies [3].

However, the authors argue that, as must always be the case, safety will remain an obvious and critical driver of the design of aircraft electrical systems. Hence future aircraft which rely at least in part on electrical propulsion will need to demonstrate a level of safety and reliability equal to current state-of-the-art More Electric Aircraft (MEA) [4]. Hence, the development of 
the specific electrical fault management (FM) technologies and systems for electrical propulsion aircraft (EPA) which will ensure flight safety must now also be of high priority.

In published literature on the early design of such aircraft, there is evidence that research into strategic application of electrical FM has still to be considered in detail [5]. In cases where electrical FM is considered as part of electrical power architecture design and proof of concept studies, this is done to better estimate system weight and losses, with demonstrations of the feasibility of the approaches or estimates of availability of underpinning technology deferred to further study [6], [7]. Additionally, in these examples the selection of very low TRL technologies indicates a low confidence in existing FM methods for electrical power system architectures for electrical propulsion applications.

Electrical architecture designs which do not effectively incorporate FM from the outset risk being proven infeasible in the future, especially where protection devices, redundancy or fault tolerance capability are required to be added to the electrical architecture retrospectively in order to meet certification standards. Thus if FM is to be convincingly incorporated into the developmental roadmap for EPA, then a methodology for the design of FM orientated electrical architectures is required. To date, no such methodology has been presented in the literature.

Furthermore, the conceptual design of future aircraft requires visibility of technology or systems integration challenges which would undermine the viability of EPA as a whole. The disparity between the state of the art (SOA) fault management technologies and the published specifications for future aircraft applications indicate that FM is a major technology challenge. For example, many of the current FM technologies on SOA aircraft are not rated for use at the higher power and voltage levels proposed for electric propulsion [8]. As the electrical safety standards for EPA are not yet fully defined, the targets for development of critical FM technologies are not yet known. This results in a high level of uncertainty in their design. Yet it would not be acceptable to wait until later in the aircraft design process (when there is less associated technology uncertainty) to scope the feasible FM solutions, as the required devices may not have been developed. By considering FM now it will be possible to specify technologies which will enable feasible FM solutions to be realized in the future.

Incorporating FM as a key functional requirement in the early design stages of future EPA also offers an opportunity to develop promising solutions that otherwise could have been overlooked and to consider electrical architectures which are optimal from a FM perspective. In this way, the critical role of FM as part of a robust design methodology realizing the potential benefits of EPA is established.

The remainder of this paper is structured as follows: Section II.A outlines the importance of FM for EPA. Section II.B presents and discusses key electrical FM design methods from the literature. In Section III a novel, robust FM oriented design framework is presented. This is then demonstrated in Section IV through a qualitative electrical architecture down-selection case study for an EPA concept featuring an electric tail cone thruster. The paper closes by drawing conclusions on the wider impact of FM oriented design practices and identifying pertinent elements of further work required in this field. 


\section{EXISTING FAULt MANAGEMENT APPROACHES}

\section{A. Defining key fault management terminology}

There is a paradigm shift required not only in the design of the electrical architectures but also in the terminology which is used. Conventionally, electrical protection design considers the possible faults that could occur at a given location on the network, and then uses that knowledge to select appropriate fault protection devices to protect against the range of anticipated faults. The proposed alternative (fault management) applies much of the same technical understanding of electrical faults, but aims to configure whole the electrical architecture from the outset with a view to the integration of effective, prioritized electrical fault protection. This enables the electrical architecture to implement a robust fault response from a combination of FM-specific devices (such as circuit breakers) and other components with possible FM functions (such as power electronic converters), as well as any inherent fault management capability of the architecture itself (such as cable overrating). Of course, it is certainly not novel to consider the upstream/downstream impact of a fault and to include some level of redundancy and overrating into the design process. Yet the stringent weight constraint and the complexity of the electrical system for an EPA, even in comparison to the level of electrical power installed on current aircraft, together with the compact configuration of the electrical system and the harsh aircraft operating environment, all require that FM must take a wider scope than conventional electrical protection.

Fault management approaches this problem with a view to only employing the devices which are proven necessary for a given FM goal, strategically locating them on the system for maximum benefit, specifying ratings of the non-fault management specific components and subsystems to complement the chosen FMS (Fault Management Strategy), acknowledging the limitations of devices and using technologies in clusters to achieve required functions where a given technology is limited.

The process of fault detection, diagnosis and location are not considered in detail in this paper, although these are important functions which would form part of the detailed FM design at a later point in the design process. The scope of FM as a whole does include these aspects, yet these will come into greater focus as the primary FM technologies develop further and the different electrical subsystems are integrated together into a complete system.

In current terminology, load management is the strategic optimization of electrical loads during flight, especially when there is an insufficient power supply. However, aside from the auxiliary loads which will of course still feature on the fully developed electrical architecture for any passenger aircraft, any form of unplanned load shedding of the large propulsive loads on the electrical system would only be implemented in a critical fault scenario. Therefore, load management becomes part of the wider FM system.

Furthermore, the electrical protection system also now has novel interfaces with the mechanical design and configuration of the aircraft and so a systems-level understanding of how an electrical fault might then impact the design of other neighboring dependent systems is required. Since in EPA the propulsion is integrated into the airframe, any electrical fault will undermine 
the optimal performance of the aircraft. More importantly, however, electrical faults threaten the ability of the aircraft to maintain the minimum propulsive power, and the safety and integrity of the aircraft structure as a whole.

\section{B. Review of FMSs and design frameworks for EPA}

The electrical architectures proposed for NASA's N-3X aircraft by Rolls-Royce [7] and GE [9] include electrical protection functionality, and highlight the significant impact that a protection system may have on the overall weight budget for an EPA. It is not clear however, whether the proposed N-3X solution is feasible or if the optimal number of protection components have been deployed [10]. This is evidenced by the pragmatic rationale behind the location and choices of devices, especially those which are at low Technology Readiness Level (TRL) for an aircraft application.

Authors in [11] identify that the electrical system Strategic Fault Response (SFR) can often be counter-intuitive when influenced by the whole aircraft design. For example, on NASA's X-57 Maxwell aircraft, if one of the wing tip thrusters were to fail, the rudder cannot correct the imbalance. As a result, either the aircraft has to be powered down to glider mode or healthy propulsors on the opposite wing need to be turned off. In this case, the EPA system may sacrifice conventional FM goals (such as maintaining power flow) to ensure that key system requirements are fulfilled.

Additional evidence of wider aircraft design influencing the electrical fault response is given in [12]. This article describes how for NASA's STARC-ABL aircraft, the contribution of the electrical system to overall thrust required varies over the flight cycle. It is conceivable that this will also result in variation of the SFR, impacting the designed-in FMS, which will need to accommodate changing operability requirements.

Furthermore, in [13] and [14], the authors describe how the electrical power system for the HYPSTAIR series hybrid propulsion system was designed using a systems approach to ensure adherence of redundancy requirements to expected certification standards. In doing so, the redundancy aspect of the FMS was factored into the design process at an early stage.

A proposed methodology of electrical system design presented in [15] determines the power requirements and the topology before assessing the impact of faults and performing fault studies. Whilst this may be a means to derive an electrical power system from first principles, the delay in considering the impact of the FM within the design overlooks the interdependency between availability and capability of different protection devices and the choice of a feasible electrical power system.

A framework for the conceptual design of aircraft to minimize environmental impact is described in [16], yet the impact of FM on the design process is not within the scope of this tool. Published work in assessing the impact of high bandwidth energy storage integration into compact DC networks highlighted the need for a comprehensive protection framework [17], which determines the protection requirements, applies relevant constraints and then selects an appropriate protection strategy. However, the means by which such a framework should implement these stages was not described, neither was an existing framework identified which adequately satisfies these requirements. 


\section{Unique challenge of EPA electrical architectures}

Whilst the focus of the FM framework presented in this paper is FM approaches for the electrical power system design of an EPA, the FM framework methodology presented in this paper may be applicable to other electrical power systems for other electrical propulsion applications in the future. However, the specific challenges of FM for EPA are distinct from those of existing electrical propulsion applications in terms of safety-critical electrical loads, mass production of highly reliable aircraft systems and stringent weight constraints. For example, whilst the Electric Vehicle (EV) industry has given much focus to the development of fault tolerant electrical propulsion systems [18]-[20] and maintaining safety-critical functions, no early-stage architecture design methodology was identified in the literature which was equivalent in terms of addressing the level of uncertainty surrounding the design of future EPA and the lack of suitable FM technologies (which may drive the need for a novel approach to fault tolerant designs).

\section{Summary of literature review and specification of required framework}

Whilst no comparable early-stage design framework exists within the literature, the articles reviewed do highlight a number of lessons learned, which require appropriate representation within any new proposed design framework. Crucially, there are a number of requirements relevant to the electrical architecture design which flow down from the whole aircraft design. These requirements form the fundamental basis of down selection of electrical system design solutions and are defined in this paper as the Platform Level Requirements (PLRs).

Additionally, it is already clear that the design of electrical architectures for EPA cannot follow a conventional approach, as thus far this has led to solutions which are sub-optimal, infeasible or overly simplistic and do not reflect the novel interfaces between the aircraft conceptual and electrical design. Therefore, a new FM oriented design framework for early-stage architecture down selection should meet the following requirements:

- incorporate FM from the outset

- map the interdependencies between the aircraft concept and the electrical system design (PLRs), particularly in relation to the FMS and SFR

- define the system goal during fault conditions so that priority FM functions can be determined

- identify the level of confidence or likely feasibility in particular FM technologies being employed within a specific developmental timeframe

- manage the large amount of uncertainty present in the design of future EPA, which is due to many design constraints being ill-defined or design decisions being based on technology projections

- offer a methodical means of reducing down the very extensive initial solution space, eliminate infeasible solutions and give some indication of priority where a number of competing requirements or outcomes exist. 


\section{OVERVIEW OF Proposed FAult MANAGEMENT ORIENTATED FrameworK}

In this section, a novel FM oriented early-stage design framework is proposed which addresses the requirements listed above. A high-level logic flow depiction of this framework is presented in Figure 2, the core details and assumptions of which are then provided later, in Figure 3.

The framework describes a comprehensive method to identify the FM requirements for a given basic aircraft concept, and hence match suitable FM technologies to desired FM actions in order to derive feasible FMSs. At each stage of the framework, the solution space is reduced until the process converges on the final down-selected electrical architectures. In this way, the identification of feasible electrical architectures is dependent on the capture of PLRs and defined FM system goal.

The FM definitions given in Section II.A are the foundation of this framework. The goal of the FM system is defined early in the process (as indicated by phase 2 in Figure 2) and then feeds into the choice of both FM actions to respond to the fault and FM technologies to implement the desired SFR. At each subsequent stage of the framework, only options which support the chosen FM goal are taken forward. In this manner, any architecture which is infeasible from an FM perspective is eliminated, providing down-selection of candidate architectures. Although it is possible that there may be growth in the number of possible solutions during the process where technologies or functions are combined together or novel solutions are identified, thus expanding the solution space, the down-selection and weighting mechanisms in the framework ensures that only feasible solutions are taken forward.

The inputs to the framework (such as the PLRs) are derived from early stage EPA concepts, the selection of these inputs requires appropriate expertise. The database gathering and determining of system goals would also require expertise in the interpretation of the aircraft standards and assessing the validity of any FM device. It may be possible to automate sections of the down-selection process. However, assessing complexity and inter-system dependencies in an automated manner will be extremely difficult and will require expert assessment and appraisal to identify feasible solutions.

To demonstrate this design framework, a case study is presented throughout Section IV, together with the framework description. In this, an example concept aircraft electrical architecture is derived to illustrate the use of the framework. A quantitative design and analysis is not within the scope of this paper due to lack of published data to perform such studies, although this process is an important one which will be required later in the development of any EPA. The benefit of using the framework is not at this point a quantifiable improvement in the physical design of the system, but rather early reductions in the design trade space through the elimination of infeasible or undesirable candidate solutions, and the identification of the aspects of the FM design which are critical to the wider aircraft feasibility (i.e. shaping informative design rules/trades). The chosen concept is a tube and wing aircraft with a rear-mounted cone thruster, similar to both the NASA STARC-ABL aircraft [12] and the Bauhaus Luftfahrt [21] propulsive fuselage aircraft, as shown in Figure 1. The input requirements to the case study, including the data in Table 1 are based on published data from early feasibility studies for the STARC-ABL aircraft 
[12].

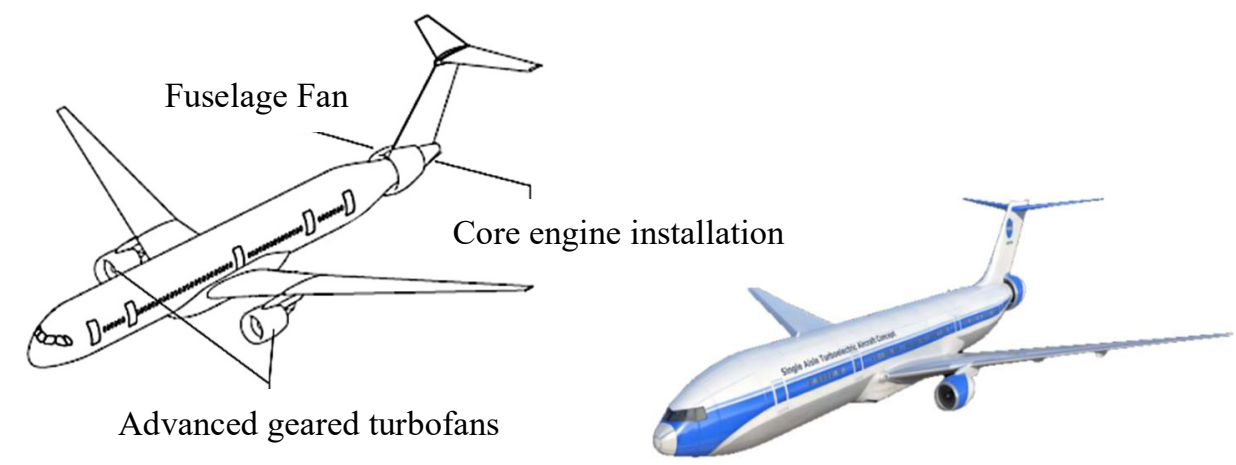

Figure 1: Illustration of Bauhaus Luftfahrt [21] and NASA concepts [32]

\section{DEMONSTRATION OF PROPOSED FM ORIENTED DESIGN FRAMEWORK}

A detailed illustration of the design framework is presented in Figure 3, expanding the key stages outlined in Figure 2 and showing the way in which assumptions have been captured. The following sections describe and discuss each major stage of the framework, drawing direct reference to the appropriate part of Figure 3 for convenience.

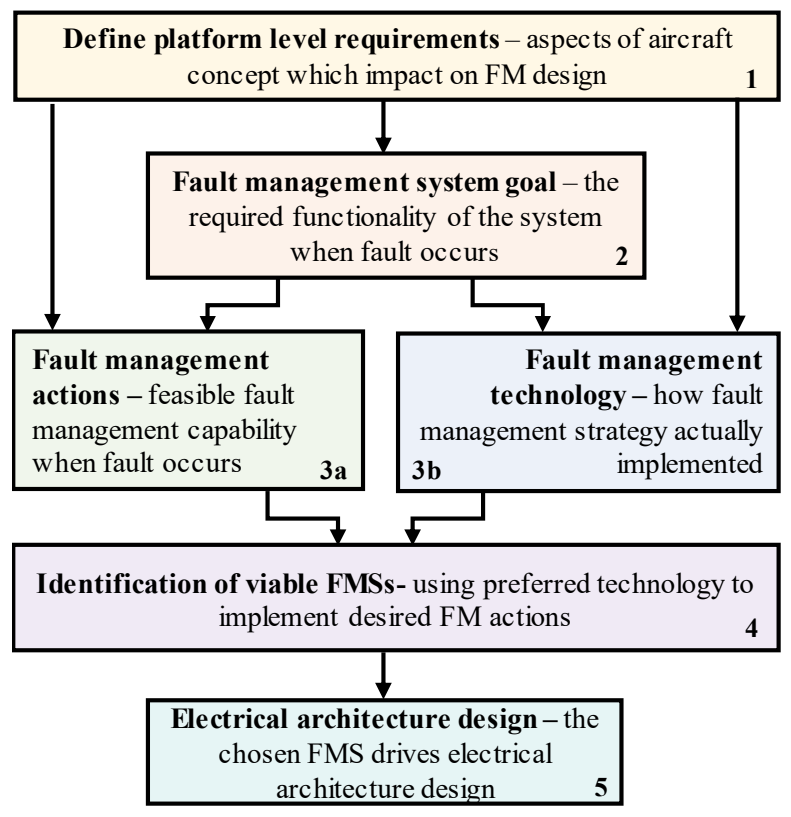

Figure 2: FM Orientated Framework Overview

\section{A. Platform level requirements ("Phase 1", Figure 3)}

By reviewing the aircraft concept, the key PLRs which have an impact on the electrical system can be defined. This mapping of the dependencies between these two facets of the system design is a key contribution of this framework. The process of weighting the PLRs relative to each other at this early point in the design process identifies the most challenging aspects of the FM design from the outset.

For the case study presented, the PLRs were based on available data from early studies performed for the STARC-ABL aircraft [12]. This aircraft concept is in the early stages of development, and therefore a limited range of verifiable data is 
available. Hence the data used in Table 1 is generalized to values similar to those available for the STARC-ABL aircraft.

Where data does not currently exist for a PLR (in this case for the "External Factors", "Pre-defined Architecture Preference" and "Customer Operational and Safety Requirements", an appropriate estimation was made. This is indicated in Table 1 by an asterisk.

\section{1) External factors}

There may also be PLRs due to external factors that impact FM design, e.g. cost or intellectual property restraints. Even if these aspects are not significant in the initial electrical design, they may result in reiterations of the framework or impact the down selection processes within the framework.

\section{2) Developmental timeframe}

Identifying the available developmental timeframe at the outset guides the selection of FM functions and technologies. The developmental timeframe for the aircraft platform determines the time period available for the maturation of relevant

TABLE 1: IDENTIFICATION OF AIRCRAFT PLATFORM LEVEL REQUIREMENTS (PLRS), INITIAL ASSUMPTIONS AND RISKS FOR CASE STUDY

\begin{tabular}{|c|c|c|c|c|}
\hline Aircraft PLR & Case Study Data & $\begin{array}{l}\text { Initial } \\
\text { Weighting }\end{array}$ & $\begin{array}{l}\text { FM Design Requirements Determining } \\
\text { Weighting Factor }\end{array}$ & Risk \\
\hline $\begin{array}{l}\text { External } \\
\text { Factors }\end{array}$ & $\begin{array}{l}\text { Proof of concept } \\
\text { aircraft, immature } \\
\text { technology* }\end{array}$ & Medium & $\begin{array}{l}\text { In the absence of data, the "External } \\
\text { Factors" are defined as the fact that the } \\
\text { aircraft is a novel concept and therefore } \\
\text { there is a lot of uncertainty in its design }\end{array}$ & $\begin{array}{l}\text { Unknown external factors could have a large } \\
\text { impact on design and may not yet be } \\
\text { anticipated }\end{array}$ \\
\hline $\begin{array}{l}\text { Developmental } \\
\text { Timeframe }\end{array}$ & Estimated EIS 2035 & High & $\begin{array}{l}\text { The complete FM system must be } \\
\text { certified for flight within the available } \\
\text { time }\end{array}$ & $\begin{array}{l}\text { FM system components do not reach high } \\
\text { TRL, the FM system does not have high } \\
\text { IRL (Integration Readiness Level) in time } \\
\text { for complete electrical system tests }\end{array}$ \\
\hline $\begin{array}{l}\text { Airframe \& } \\
\text { BLI }\end{array}$ & Single BLI fan at rear & Medium & $\begin{array}{l}\text { The use of BLI is required, loss of power } \\
\text { to the fan is detrimental causing drag and } \\
\text { dependence on mechanical compensation } \\
\text { measures should be avoided }\end{array}$ & $\begin{array}{l}\text { Mechanical/ airframe design variations may } \\
\text { change the size of the fan and thus the power } \\
\text { demand, mechanical responses to electrical } \\
\text { failure at the fan may be preferred }\end{array}$ \\
\hline $\begin{array}{l}\text { Weight } \\
\text { Budget }\end{array}$ & $\begin{array}{l}\text { Expected weight } \\
\text { budget of total } \\
\text { electrical system } \\
\text { (not including any } \\
\text { energy storage) is } \\
\text { approx. } 1400 \mathrm{~kg}\end{array}$ & High & $\begin{array}{l}\text { The additional weight of the electrical } \\
\text { drive train must be minimized and is } \\
\text { assumed to be offset by the fuel, } \\
\text { emissions and noise savings for this EPA } \\
\text { concept to be viable }\end{array}$ & $\begin{array}{l}\text { FM system may not be viable within the } \\
\text { given weight budget, FM options may be } \\
\text { considerably limited, innovative FM } \\
\text { measures may be needed }\end{array}$ \\
\hline $\begin{array}{l}\text { Percentage } \\
\text { Hybridization } \\
\text { and Location } \\
\text { of Propulsion }\end{array}$ & $\begin{array}{l}\text { Up to } 50 \% \text { of total } \\
\text { thrust at top of } \\
\text { climb electrical, } \\
\text { power delivered to } \\
\text { rear thruster }\end{array}$ & High & $\begin{array}{l}\text { The maximum power demand must be } \\
\text { maintained, the } 50 \% \text { mix is assumed } \\
\text { optimal and feasible, power must be } \\
\text { distributed to different parts of the } \\
\text { aircraft, single large fan at rear is } \\
\text { preferred to wing mounted fans }\end{array}$ & $\begin{array}{l}\text { The electrical drive system cannot reliably } \\
\text { supply the max power requirement, fitting } \\
\text { the large components of the electrical FM } \\
\text { system within the airframe at the required } \\
\text { locations is not possible or carries risks }\end{array}$ \\
\hline $\begin{array}{l}\text { Thermal } \\
\text { Management }\end{array}$ & $\begin{array}{l}\text { Non-superconducting } \\
\text { system, must } \\
\text { minimize thermal } \\
\text { loads }\end{array}$ & Low & $\begin{array}{l}\text { Heat generated by components needs to be } \\
\text { easily dissipated and components have to } \\
\text { be operated in a temperature controlled } \\
\text { environment to enable optimal } \\
\text { performance }\end{array}$ & $\begin{array}{l}\text { The thermal loads will reduce the overall } \\
\text { efficiency \& power will be required to } \\
\text { dissipate the heat. Uncontrolled variation in } \\
\text { temperature of devices causes failure or } \\
\text { constrains the location of devices within the } \\
\text { aircraft }\end{array}$ \\
\hline $\begin{array}{l}\text { Typical Flight } \\
\text { Plan \& PAX }\end{array}$ & $\begin{array}{l}150 \text { PAX, single aisle } \\
\text { passenger aircraft }\end{array}$ & Low & $\begin{array}{l}\text { The electrical propulsion system must meet } \\
\text { certification standards for single aisle civil } \\
\text { aircraft }\end{array}$ & $\begin{array}{l}\text { The certification and safety requirements will } \\
\text { significantly constrain or direct the choice of } \\
\text { FM solutions }\end{array}$ \\
\hline $\begin{array}{l}\text { Pre-defined } \\
\text { Architecture } \\
\text { Preference }\end{array}$ & $\begin{array}{l}\text { DC distribution } \\
\text { network* }\end{array}$ & Low & $\begin{array}{l}\text { It is assumed that this is the design } \\
\text { preference for the first iteration of the } \\
\text { design framework }\end{array}$ & $\begin{array}{l}\text { Any bias towards this particular solution may } \\
\text { risk alternatives being overlooked }\end{array}$ \\
\hline $\begin{array}{l}\text { Customer } \\
\text { Operational } \\
\text { and Safety } \\
\text { Requirements }\end{array}$ & $\begin{array}{l}\text { Assumed comparable } \\
\text { to ETOPS } \\
\text { requirements for a } \\
\text { similar sized } \\
\text { passenger aircraft* }\end{array}$ & Low & $\begin{array}{l}\text { The customer requirements for the } \\
\text { electrical system design have to be } \\
\text { specified and in the absence of data, the } \\
\text { requirement has been based on existing } \\
\text { safety requirements for similar aircraft }\end{array}$ & $\begin{array}{l}\text { These requirements might not be defined and } \\
\text { may vary largely over the development of the } \\
\text { aircraft }\end{array}$ \\
\hline
\end{tabular}

*where data does not exist in the literature an appropriate estimation has been made. 


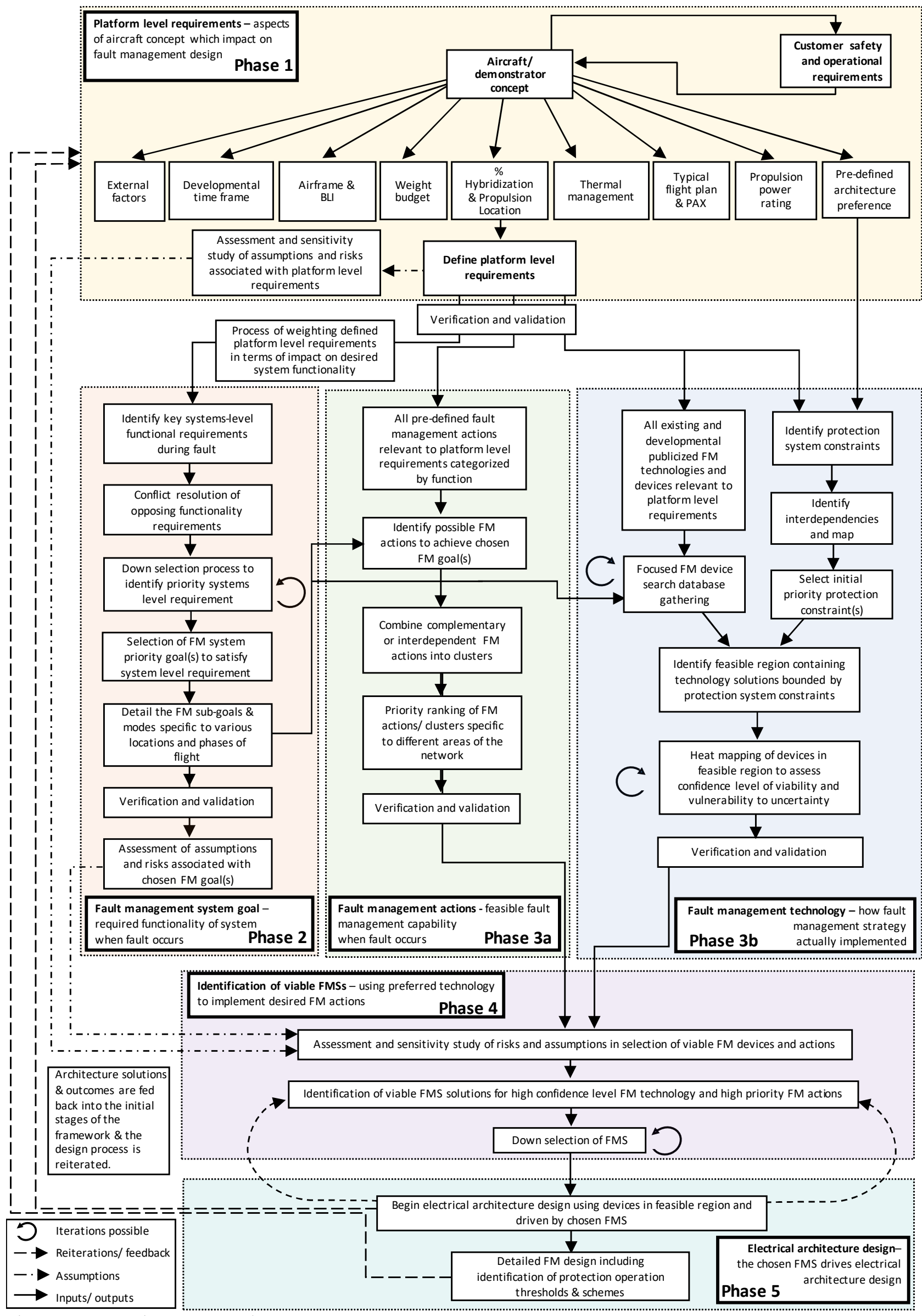

Figure 3: FM Design Framework 
technologies to the required TRL for demonstration/production depending on the platform aims. This is distinct from the point of Entry into Service (EIS), since the detailed specification of the electrical system must occur well ahead of the initial aircraft becoming available on the market. An alternative metric is the point of Initial Operational Capability (IOC) which is when the first aircraft of its kind would enter service.

\section{3) Airframe propulsion integration}

The aerodynamics of the airframe structure are linked to the FM requirements for the aircraft. A key driver for electrical propulsion is that it enables novel airframe configurations and the use of improved aerodynamics to bring efficiency improvements to overall aircraft operation [22]. In particular, Boundary Layer Ingestion (BLI) is expected to reduce aircraft drag, enabling the aircraft to achieve the same amount of thrust with less propulsive power. However, the use of an electrical motor to power a propulsor fan as part of an integrated BLI fan design creates a new interface between the aerodynamics of the aircraft and the electrical system.

\section{4) Weight budget}

It is essential to establish during the first stage of the framework the available weight budget for the aircraft. The weight budget for the aircraft will also have an impact on the FM design. A number of aircraft concepts have been proposed where the weight of the FM system is not explicitly included in the total electrical weight budget, e.g. [5], [23]. However, FM specific devices and components with an FM capability will form a non-negligible proportion of the available weight budget.

\section{5) Percentage hybridization and distribution of propulsion}

The degree of hybridization for the aircraft and the location within the airframe of the electrical propulsors will also influence FM design, because these influence aspects of the electrical architecture such the maximum power rating of the system and the required length of cables between components.

\section{6) Thermal management}

Thermal management is a key aspect of system design for both superconducting and conventional aircraft systems. Any losses in electrical components, including FM devices, will create a thermal load which will need to be safely and effectively dissipated.

\section{7) Aircraft type and $P A X$}

The size of an aircraft will influence the design of FM solutions. Indeed, the segment of the market for which the aircraft is intended is often linked to the developmental time frame. 


\section{8) Propulsion power rating}

The choice of FM technology must match the power (and by implication, voltage) requirements of the electrical architecture which will be determined by the required power output of the propulsor motors. These electrical power requirements also have implications for the number of power channels required, as the total required power flow could be split into multiple channels to accommodate limitations in the rating of devices and realize system redundancy, in turn forming part of the FM approach.

\section{9) Pre-defined architecture preference}

If there is a legacy preferred solution (resulting from IP protection or from a wider commercial motive), then identifying the scope of this PLR in the initial stages of the process means that it is possible to record its effect on the downstream design decisions. This is particularly evident in the choice between AC and DC systems, and possibly in the various locations of the distributed propulsion.

\section{0) Customer operational and safety requirements}

The customer requirements related to airport logistics and government and international safety regulations provide the baseline safety level for the aircraft [24], which then helps formulate the PLRs for the FM system. There may also be various customer requirements which will directly impact on the electrical system design, for example where the safety or required training for maintenance personnel working on the aircraft would dictate that particular voltage levels are undesirable or require special safety measures, as is the case in marine vessels [25]. Operational requirements will need to be considered throughout the entire flight cycle since different points in the cycle will correspond to different failure modes and requirements. This will impact on the detailed FM design ("Phase 5" in Figure 3) and on the critical corner points in the design.

\section{1) Weighting of platform level requirements}

Classification of the impact rating of PLRs captures the sensitivity of the electrical design to changes in the aircraft conceptual design. Hence, once all PLRs have been identified, they are weighted according to the level of direct impact each requirement will have on the selection of the FM system goal. In doing so, the ensuing down selection process of key systems level requirements is simplified. The weighting of the PLRs is also used later in the framework to determine priority technology constraints (see Section IV.D). The initial weighting of the PLRs is based on engineering judgement, but this would be standardized through repeated runs of multiple concepts through the framework.

For the case study presented, a greater weighting is arbitrarily assigned to the location and degree of hybridization, weight budget and the developmental timeframe. These are highlighted in bold in Table 1. 


\section{2) Assumptions and risks}

The risks associated with asserting any particular assumption and the restriction this may place on the options presented further down the design process must be recognized. However, most assumptions are likely to relate to unknowns in the design which require some extrapolation of available knowledge or data. This leads to the key risk that the chosen FM option is a solution which is infeasible or uncompetitive. Thus, after defining the PLR, and then after later stages in the framework ("Phase 2", "3a", "3b" in Figure 3), sensitivity studies are proposed in order to identify and assess the assumptions and risks associated with any design decisions that have been made.

For the case study presented, the risks associated with the high impact PLRs are listed in Table 1.

\section{B. Fault management system goal ("Phase 2", Fig 3.)}

In any aircraft electrical power system, there are many possible responses to the detection of a fault. A strategic FM response is needed to ensure safety of flight and to satisfy the PLRs.

\section{1) System level functional requirements}

To ultimately determine the strategic FM response for a given aircraft, the desired system functionalities first have to be identified. Since there may be conflicting system functionalities which cannot be fulfilled simultaneously, the system functionalities are ranked in terms of priority. The most important system functionality can then be down selected.

By using the desired response of the electrical system during a fault to determine the FM goal, only the necessary FM functions are included in the design. This leads to a solution which is directly driven by the critical FM requirements. Hence the proposed framework presents an important improvement on existing methodologies.

For the case study presented, the functional requirements are driven by the need to deliver power to the fan reliably with the technology and architectures which are actually viable for a pre-2035 timeframe. These are listed below, ranked in terms of priority:

1. Ensure sufficient power is supplied to key electrical loads, maintaining flight stability

2. Ensure the integrity and continued capability of the electrical system

3. Ensure that BLI propulsion is maintained

4. Minimize the thermal loads and excessive mechanical loading of the BLI fan 


\section{2) Selection of FM system priority goal}

After determining the priority functional requirement, the FM-specific priority goal required to satisfy this requirement can then be derived.

For the case study presented, the priority goal for the FM system is "maintain minimum power flow to the rear fan when an electrical fault occurs upstream from the fan".

\section{3) FM sub-goals}

The criticality of the electrical propulsion system may alter over flight (especially where the percentage of total thrust coming from the electrical system varies). Hence, within the FM system goal there are operating modes and sub-goals which can be defined for both critical (such as take-off) and non-critical stages of flight (such as taxi). An example list of FM modes and sub-goals are described in Table 2. For the case study presented, the selected FM sub-goals are shown later as a function of flight phase, in Table 6 (complemented by subsequent framework outputs).

\section{4) Assumptions and risks}

The final stage of FM goal setting is to undertake a final check of the validity of assumptions made, and evaluate the risk of incorrect assumptions. For particularly high-risk assumptions where validity is not sufficiently assured, further investigative work is required to progress through the framework.

For the case study presented, a number of requirements are implicit in the realization of the FM system goal (such as the requirement that the FM response should not cause fault propagation or cascaded faults). However, both limitations on the FM system goal and sub-goals specific to locations on the network would be determined in later iterations of the framework for this particular case, as the FMS and architecture is not yet known.

\section{Fault management actions ("Phase 3a", Fig. 3)}

Following the establishment of the desired FM priority and sub goals, FM actions, which are the potential means of realizing these FM goals, can then be defined. FM actions include both conventional electrical protection mechanisms ("conventional FM actions") and architecture choices ("system overrating”), examples of which are shown in Table 3.

TABle 2: Possible FM Modes, GoAls AND the Associated Risks AND

\begin{tabular}{|l|l|}
\multicolumn{2}{l}{ ASSUMPTIONS } \\
\hline Possible FM Modes & Possible FM Sub-goals \\
\hline Pre-empt fault & $\begin{array}{l}\text { Reconfigure/ increase power availability } \\
\text { Reconfigure power flow } \\
\text { De-energize complete network or zone }\end{array}$ \\
\hline $\begin{array}{l}\text { No change \& monitor } \\
\text { fault }\end{array}$ & Maintain power flow and architecture \\
\hline React to fault & $\begin{array}{l}\text { Reconfigure power flow } \\
\text { Reconfigure/ increase power availability } \\
\text { Maintain electrical power flow architecture } \\
\text { Remove faulted section from network } \\
\\
\text { De-energize complete network or zone } \\
\text { Maintain power availability }\end{array}$ \\
\hline
\end{tabular}


TABLE 3: FM ACTIONS

\begin{tabular}{|l|l|}
\hline System Overrating & Conventional FM Actions \\
\hline Redundant components & Fault current interruption/ \\
Fault tolerant components & diversion \\
Multiple power flow channels & Limitation of impact of fault \\
Additional or alternative power & current energy \\
sources & Physical isolation of faulted \\
Additional or alternative & network \\
propulsion sources & Fault detection, diagnosis and \\
& locating \\
\hline
\end{tabular}

For the case study presented, the example list in Table 3 is further expanded in Figure 4, which also captures candidate technologies as part of "conventional FM actions" and their confidence levels aligned with the heaviest weighted PLRs. The clustering approach illustrated is utilized to facilitate the process of matching actions and technologies to form a viable FMS This adds value to the framework as it succinctly identifies components capable of implementing multiple FM actions as well as combinations of FM actions for which no solution currently exists. Although the means of "system overrating" identified are obvious, the framework captures the ways in which these would be used effectively in combination with other FM actions to formulate a strategic fault response, rather than simply including an element of redundancy in the electrical architecture.

Additionally, the use of alternative electrical or engine propulsion has not been included in the list of possible FM actions since the PLRs for this case study state that there is only one single propulsor fan and an assumption has been made that the engines cannot compensate for loss of electrical propulsion.

\section{Fault management technology ("Phase 3b”, Fig 3.)}

The next stage of the FM framework is the identification of the available and preferred FM technologies. Before scoping the landscape of various protection devices, target FM technologies are identified. This is because outputs from earlier stages in the framework, e.g. aircraft PLRs, can identify specific aspects of design, e.g. preference for a DC system, which are relevant to the choice of protection technologies. A targeted approach to selecting protection technologies is valuable as it reduces the solution space early in the design process.

The process of establishing a baseline database, selecting target technologies, identifying and quantifying (as far as possible) the constraints on the choice of technology, mapping the interdependency of constraints, prioritizing the constraints on the design process has already been established and is described in [26]. By considering the key constraints, devices which are not within the feasible region can be eliminated and only viable FM technologies can then be used to form FMS in the next stage of the framework.

To determine if devices which do not yet exist for an aircraft application may develop sufficiently to enter the feasible region in the future, or for where the IOC date is very far in the future, a process of heat mapping is applied. This novel aspect of the framework involves determining a confidence level ("Low", "Medium" or "High") for individual technologies based on their current TRL [27] and IRL [28] and then extrapolating to the point of IOC to estimate the level of development that will have been achieved. This rating can then be updated as constraints shift over the developmental time frame. 


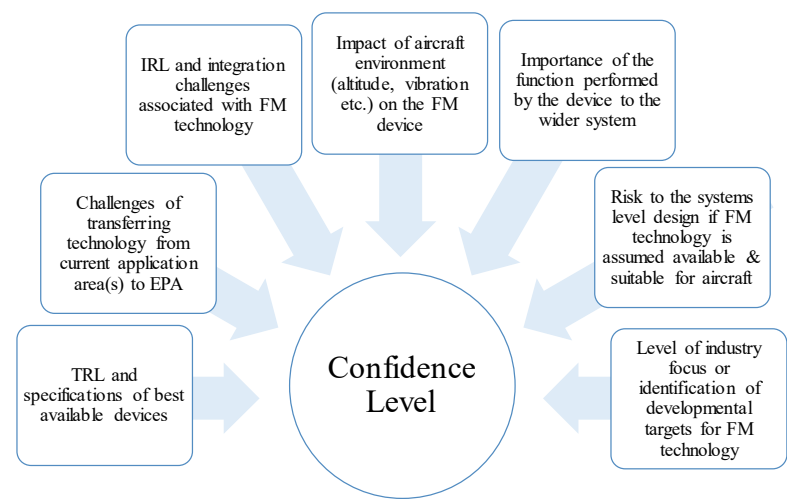

Figure 4: Factors determining the confidence level of FM technologies for use within a future EPA FMS

The heat mapping can also be applied later in the process to the range of FMS options to determine the viability confidence of the combined effect of different FM technologies. The confidence level of a number of different components or architecture features is limited by the lowest individual confidence level in the cluster. The maturity of a particular combination of devices for use on an aircraft will also impact the combined confidence rating, as will the dependency of the components on each other for future development of technologies or subsystems. It is possible that the combined effect of a number of components leads to a better confidence level overall, where a particular solution is more robust due to increased redundancy or if components compensate for each other in the case of failed operation.

Since this process is based on estimating future development and trends from the current status of the FM devices, it is imperative that the best available publicized data is constantly added to the FM database, so that understanding of the current FM technology landscape is maintained and an appropriate basis for heat mapping is achieved. This also would enable identification of technology gaps and their development priority.

For the case study presented, the FM technologies which are relevant to the PLRs defined in Table 1 are shown in Table 4, based on data presented in [26]. It is assumed that from the range of constraints discussed in [26], the most important constraints are weight, speed of SFR, efficiency and certification, and these are identified and mapped in Figure 5. Note that fuses and pyro-based switches were not considered here as their non-resettable nature does not facilitate their use as a fully controllable device. However, these technologies may still be employed to provide backup protection functionality.

From Figure 5, it is clear that the weight of the FM system is linked to both the speed of the FM response, and efficiency, and is in itself a significant aircraft design constraint. Therefore, FM system weight is chosen as the priority constraint or Most Important Constraint (MIC) for the initial iteration of the framework case study. The confidence level for each device considered in the case study is given in Table 4, and the criteria which were used to determine the confidence level of devices are shown in Figure 4. Confidence levels for future aircraft switchgear technologies are particularly difficult to ascertain as there is a limited range of publicized research targets for these devices within an EPA [29]. So with a lack of consensus on the roadmap for circuit breaker technology, there is no metric against which to assess the confidence level of these devices. Furthermore, the authors argue that there are some technologies (such as circuit breakers) which may simply be necessary even 
if they are bulky, heavy, slow to operate or inefficient because they perform critical FM functionalities. For this reason, some technologies which are low confidence in Table 4 (such as SSCBs) have been included for consideration in the FMS selection, so that the FM system sub-goals can be achieved.

Furthermore, integrating FM devices into an aircraft system may be significantly more difficult than placing these within a terrestrial grid network. This is the reasoning behind the "Low" confidence rating of the fault current limiting devices, as the cryogenic cooling system has to be considered in the weight budget. As fuses are a mature technology for aircraft electrical systems it is assumed that these devices could be easily integrated into future EPA systems, and so these devices are the only technology with a "High" confidence level as they have a simple function and may be necessary as a last resort physical fault isolation mechanism, if switchgear on the faulted zone should fail.

\section{E. Identification of viable FM solutions ("Phase 4", Fig. 3)}

In order to implement the desired FM goals for a specific case, FM technologies combined with other enabling aspects of system overrating can be compiled into a selection of feasible, comprehensive FMSs. Down selection of a preferred FMS solution is then performed through qualitative judgement and quantitative assessment (for example, through modelling and simulation-based studies).

For the case study presented, technologies which can implement the desired FM goals were selected, with reference to the FM action map shown in Figure 6. A description of the selected FMSs and associated technologies for the case study is given in Table 5. There are also a number of assumptions underlying each FMS and these are noted, although the most common assumption at this stage is that the devices in the FMS are available within the developmental timeframe.

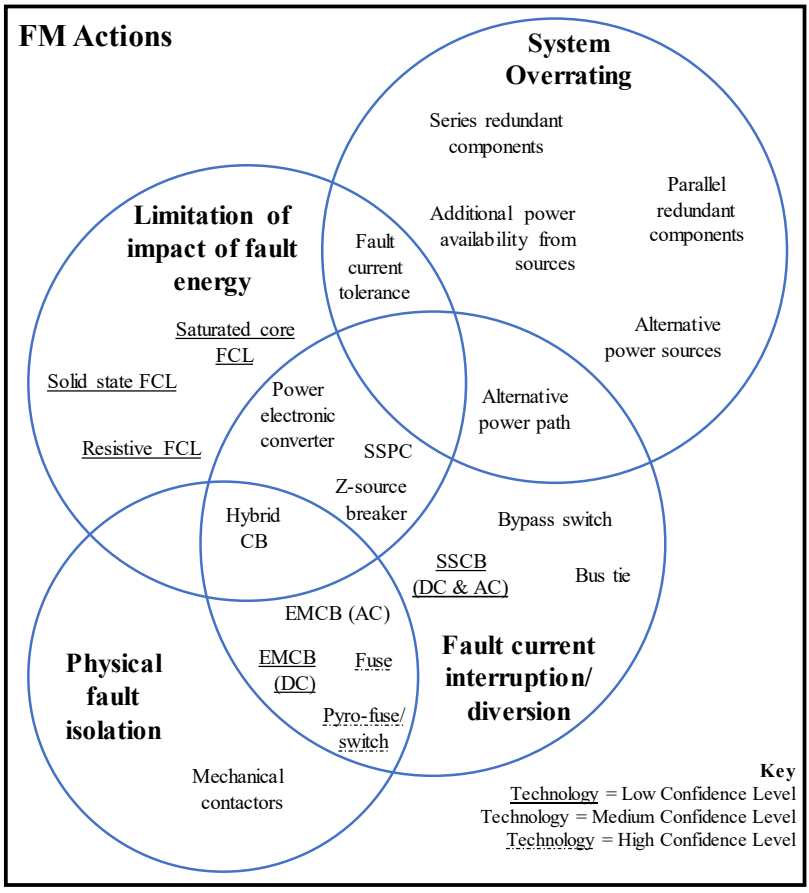

Figure 6: FM Actions Venn Diagram

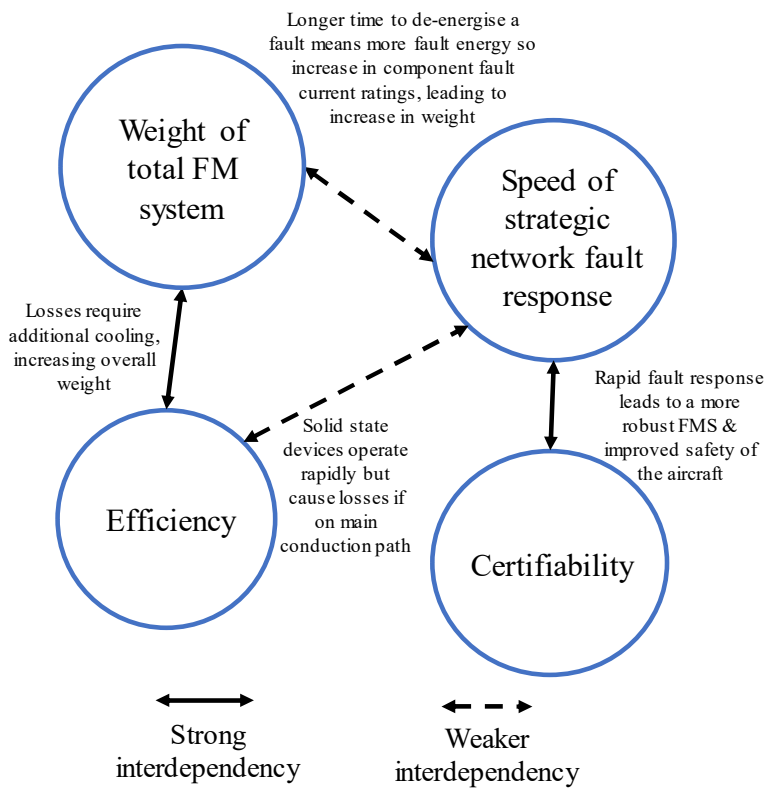

Figure 5: Mapping of priority constraints for case study 
The case study is intended as an illustration of how the process of defining a range of possible FMSs and then performing down-selection operates, and the way in which both availability of FM technology and the FM technology requirements need to be matched. There may be many more FMS options, especially if location-specific FM strategies are considered. However, this is where expertise is necessary in the application of the framework in that the three FMS options presented here would generally be considered by the authors to be the three examples which best demonstrate the value of the early stage design framework.

This method of compiling an FMS based on different solutions to meet the most challenging constraints marks a novel approach to the application of FM to EPA systems. This framework also offers a model for designing a robust FM where the complete system and interactions are considered, together with the rationale behind the selection and location of each individual FM device.

For the case study presented, the candidate FMSs were subjected to a down selection process, the findings of which are shown in Table 6. The ideal FMS is robust and is achievable within the selected priority constraints. Where an FMS is "Better" or "Worse" in regards to a particular constraint, reference is made to Table 6, to ascertain the impact of that constraint on the other constraints important to the FM system design.

\begin{tabular}{|c|c|c|c|}
\hline \multicolumn{3}{|c|}{ FROM DATABASE of CURRENT FM DEVICES } & \multirow{2}{*}{$\begin{array}{l}\text { FOR GIVEN EIS } \\
\text { Confidence Level } \\
\text { for Case Study } \\
\text { Aircraft }\end{array}$} \\
\hline Device & $\begin{array}{l}\text { TRL of } \\
\text { Available } \\
\text { Devices }\end{array}$ & $\begin{array}{l}\text { Current Development } \\
\text { Application Area(s) }\end{array}$ & \\
\hline $\begin{array}{l}\text { Solid State } \\
\text { Power } \\
\text { Controller }\end{array}$ & Medium/ High & Aircraft & Medium \\
\hline $\begin{array}{l}\text { Solid State } \\
\text { Circuit Breaker } \\
\text { (AC) }\end{array}$ & Low & $\begin{array}{l}\text { Naval, Traction } \\
\text { systems }\end{array}$ & Low \\
\hline $\begin{array}{l}\text { Solid State } \\
\text { Circuit Breaker } \\
\text { (DC) }\end{array}$ & Low & $\begin{array}{l}\text { Naval, HVDC, } \\
\text { Traction systems }\end{array}$ & Low \\
\hline EMCB (AC) & High & $\begin{array}{l}\text { Terrestrial Grid, } \\
\text { traction, }\end{array}$ & Medium \\
\hline EMCB (DC) & High & $\begin{array}{l}\text { Terrestrial Grid, } \\
\text { traction, HVDC }\end{array}$ & Low \\
\hline $\begin{array}{l}\text { Hybrid Circuit } \\
\text { Breaker }\end{array}$ & Low & $\begin{array}{l}\text { Terrestrial Grid, } \\
\text { traction, being } \\
\text { developed at low TRL } \\
\text { for aircraft }\end{array}$ & Medium \\
\hline $\begin{array}{l}\text { Mechanical } \\
\text { Fuse }\end{array}$ & High & Aircraft & High \\
\hline $\begin{array}{l}\text { Power } \\
\text { Electronic } \\
\text { Converter }\end{array}$ & Low & $\begin{array}{l}\text { HVDC, Naval \& } \\
\text { Marine, Traction }\end{array}$ & Medium \\
\hline $\begin{array}{l}\text { Mechanical } \\
\text { Contactors }\end{array}$ & High & Aircraft, Naval, HVDC & Medium \\
\hline $\begin{array}{l}\text { Z-source } \\
\text { breaker (DC) }\end{array}$ & Medium & Naval MVDC & Medium \\
\hline Bypass Switch & Low & Aircraft & Medium \\
\hline Bus Tie & Medium/ High & Aircraft & Medium \\
\hline Resistive & High & Terrestrial grid, naval & Low \\
\hline Saturated Core & High & Terrestrial grid & Low \\
\hline Solid State & High & Terrestrial grid & Low \\
\hline
\end{tabular}


TABLE 5: POSSIBLE FMS OPTIONS FOR CASE STUDY

\begin{tabular}{|c|c|c|c|c|}
\hline $\begin{array}{l}\text { FMS } \\
\text { Choice } \\
\text { (see }\end{array}$ & $\begin{array}{l}\text { FMS } \\
\text { solution to } \\
\text { priority } \\
\text { constraint }\end{array}$ & $\begin{array}{l}\text { Key Actions and Configuration of } \\
\text { Possible FMS }\end{array}$ & $\begin{array}{l}\text { Selected FM } \\
\text { Technologies }\end{array}$ & Assumptions Associated with FMS \\
\hline \multirow[t]{4}{*}{ A } & \multirow{4}{*}{$\begin{array}{l}\text { No DC } \\
\text { circuit } \\
\text { breakers }\end{array}$} & \multirow{4}{*}{$\begin{array}{ll}\text { 1. } & \text { De-energize the entire DC } \\
\text { network } \\
\text { 2. Use of ESS located towards the } \\
\text { propulsive motor to provide short } \\
\text { term power supply to motor } \\
\text { 3. Separate power channels for } \\
\text { redundancy } \\
\text { 4. Dual feed ( } 2 \text { converters) to motor } \\
\text { 5. AC breakers provide physical } \\
\text { isolation of faulted DC network } \\
\text { and isolation of machines } \\
\text { 6. } \begin{array}{l}\text { Overrating of channels, single } \\
\text { channel can provide maximum } \\
\text { power to load }\end{array} \\
\end{array}$} & AC EM breakers & \multirow{4}{*}{$\begin{array}{l}\text { 1. The downtime of the affected network does not } \\
\text { have a noticeably detrimental impact on the } \\
\text { propulsive power } \\
\text { 2. ESS with sufficient energy density can supply } \\
\text { power sufficiently fast through the converter to } \\
\text { maintain security of supply } \\
\text { 3. Overrating of devices does not cause excessive } \\
\text { weight penalty } \\
\text { 4. The converters have a power density acceptable } \\
\text { for an aircraft application } \\
\text { 5. ESS can be stored within the airframe in the } \\
\text { vicinity of the DC busbar }\end{array}$} \\
\hline & & & $\begin{array}{l}\text { Power electronic } \\
\text { converters }\end{array}$ & \\
\hline & & & $\begin{array}{l}\text { High bandwidth } \\
\text { ESS }\end{array}$ & \\
\hline & & & $\begin{array}{l}\text { Non-current } \\
\text { interrupting DC } \\
\text { switches }\end{array}$ & \\
\hline \multirow[t]{4}{*}{$\mathrm{B}$} & \multirow{4}{*}{$\begin{array}{l}\text { Number of } \\
\text { DC circuit } \\
\text { breakers } \\
\text { limited on } \\
\text { the network }\end{array}$} & \multirow{4}{*}{$\begin{array}{l}\text { 1. AC and DC SSCBs on network to } \\
\text { rapidly isolate the faulted network } \\
\text { 2. AC and DC bus-tie switches to } \\
\text { reroute power between channels } \\
\text { 3. DC switches to reconfigure and to } \\
\text { isolate the specific fault on cables } \\
\text { 4. Converters switching capability } \\
\text { for back-up } \\
\text { 5. Increased fault current tolerance } \\
\text { for inverter as on single power } \\
\text { channel }\end{array}$} & $\begin{array}{l}\text { SSCBs (AC and } \\
\text { DC) }\end{array}$ & \multirow{4}{*}{$\begin{array}{l}\text { 1. The SSCBs for the DC network are of a sufficient } \\
\text { power density } \\
\text { Lack of current interruption capability on each of } \\
\text { the DC cables is acceptable for certification } \\
\text { standards } \\
\text { 3. ESS is not available or unsuitable for this } \\
\text { configuration }\end{array}$} \\
\hline & & & $\begin{array}{l}\text { Non-current } \\
\text { interrupting DC } \\
\text { switches }\end{array}$ & \\
\hline & & & $\begin{array}{l}\text { Power electronic } \\
\text { converters }\end{array}$ & \\
\hline & & & $\begin{array}{l}\mathrm{AC} \text { and } \mathrm{DC} \text { bus } \\
\text { tie switches }\end{array}$ & \\
\hline $\mathrm{C}$ & $\begin{array}{l}\text { Choice of } \\
\text { an } \\
\text { alternative } \\
\text { technology } \\
\text { to SSCB } \\
\text { with } \\
\text { reduced } \\
\text { weight }\end{array}$ & $\begin{array}{ll}\text { 1. } & \text { Parallel redundancy on all DC } \\
\text { power paths } \\
\text { 2. Components rated to single } \\
\text { channel limited maximum fault } \\
\text { current rating } \\
\text { 3. Z-source fast fault isolation } \\
\text { 4. AC EMCB breakers at machines } \\
\text { on the AC side for physical fault } \\
\text { isolation }\end{array}$ & $\begin{array}{l}\text { Multiple z-source } \\
\text { breakers }\end{array}$ & 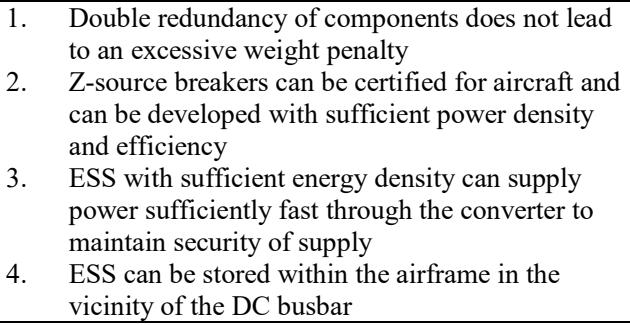 \\
\hline
\end{tabular}

Since the case study aircraft utilizes a single propulsive load, the FMS at the load end of the electrical network is relatively straightforward. The only difference in protection for this zone is the use of "System Overrating", with Option A utilizing parallel redundancy and Option B using increased fault current tolerance of the inverter. As the AC fault isolation mechanism across the three FMSs is largely the same (based on the assumption that suitable AC breakers are available), with the exception of AC side bus-ties in option B, the DC FM operation is the basis on which to differentiate the FMS options. The weights and efficiencies of different DC current interruption devices were compared in [30], which provides a basis to evaluate the relative weights, speed of response and efficiency of the candidate DC FM strategies, as shown in Table 6.

Certification may require there to be physical isolation possible at key points on the network (including the DC network), which is why option A is considered less ideal. Also protection settings may have to be adjusted if the network configuration changes, so isolating channels reduces the amount of adaptive control required in the short time period available to implement an SFR[17]. Any SFR that depends on sequential operation is more vulnerable to failures of the FM system itself, where functional FM devices are unable to operate due to the failure of some other FM device or network component. Whilst such options allow a weight reduction where there are a reduced number of DC breakers required, it is assumed that this will be unacceptable for certification purposes due to an extended time period before the system is completely re-energized or reconfigured. 
For the case study aircraft, it is preferable to maximize efficiency, and as such, solid-state protection devices with their typically higher conduction losses are undesirable. Therefore, the lack of solid-state devices in option A is preferential, whereas the large number of Z-source breakers (which utilize a solid-state device on the normal current path) in option $\mathrm{C}$ would be problematic.

The chosen FMS for this case study initial iteration is therefore option B as it satisfies the MIC whilst also not jeopardizing the FM being viable within the bounds of the other priority constraints.

In future iterations, aspects of option A and C could be combined with the original embodiment of FMS B in order to make the fault response even more robust. In particular, an Energy Storage System (ESS) could be added on the DC bus bar and included in the FMS or a parallel inverter/motor combination could be included.

\section{F. Architecture design ("Phase 5", Fig. 3)}

At this stage of the process, the FMS options have been identified for the case study, viable electrical architectures for the aircraft can now be determined by using expert knowledge to identify possible, sensible electrical architectures which include all the required architecture features and FM technologies.

From the range of possible architectures for the case study presented, one possible example architecture relating to FMS option B is shown in Figure 7. It should be noted that there is often more than one means of implementing an FMS on an architecture, especially in the first iteration of the framework where location specific goals may not yet be defined. There are not a pre-defined set of architectures which are simply updated at this point, but there may be architectures features which have been defined in earlier stages of the framework. This is captured in the section of the framework labelled "Pre-defined architecture preference" in Section IV.A.9) where a preference for a particular architecture type or feature (such as DC distribution) can be specified.

\section{G. Detailed fault management design}

Once the baseline architectures have been established for the down selected FMSs, detailed design of FM operation, including setting trip thresholds for the protection devices would be completed. This final stage has not been undertaken for the case study presented as it is out of scope of the paper.
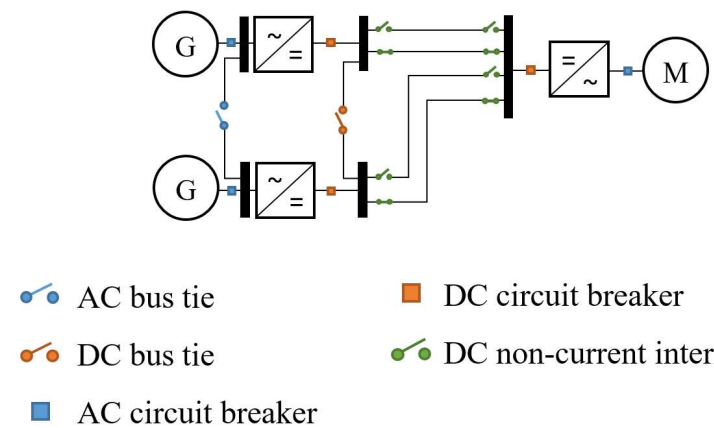

$\square$ DC circuit breaker

o DC non-current interrupting switch

Figure 7: Possible architecture for FMS option B 
TABLE 6: DOWN SELECTION OF FMS OPTIONS

\begin{tabular}{|c|c|c|c|c|}
\hline \multirow{2}{*}{$\begin{array}{l}\text { Priority } \\
\text { Ranking }\end{array}$} & \multirow{2}{*}{$\begin{array}{l}\text { Chosen High Priority } \\
\text { Constraints }\end{array}$} & \multicolumn{3}{|c|}{ Comparison of Possible FMS Solutions } \\
\hline & & Option A & Option B & Option C \\
\hline 1 & $\begin{array}{l}\text { Weight of Total FM } \\
\text { system }\end{array}$ & Better & - & Worse \\
\hline 2 & Speed of SFR & Worse & Better & Better \\
\hline 3 & Efficiency & Better & - & Worse \\
\hline 4 & Certifiability & Worse & - & Better \\
\hline $\begin{array}{l}\text { Flight } \\
\text { Phase }\end{array}$ & Sub-goals & \multicolumn{3}{|c|}{ How is the required sub-goal achieved? } \\
\hline \multirow[t]{2}{*}{ Critical } & $\begin{array}{l}\text { Reconfiguration to } \\
\text { maintain power flow }\end{array}$ & $\begin{array}{l}\text { Cross feeder DC cables } \\
\text { ESS on both DC bus bars } \\
\text { Dual motor feeder cables } \\
\text { Components rated for single } \\
\text { channel power delivery }\end{array}$ & $\begin{array}{l}\text { Bus ties on AC and DC bus bars } \\
\text { Redundant DC cables with DC } \\
\text { bypass switches }\end{array}$ & $\begin{array}{l}\text { Z-source hybrid breakers on } \\
\text { DC network \& AC breakers }\end{array}$ \\
\hline & $\begin{array}{l}\text { Redundant Power } \\
\text { Rapidly Available }\end{array}$ & $\begin{array}{l}\text { ESS located at DC bus bar for } \\
\text { short term supply to motor via } \\
\text { converter }\end{array}$ & $\begin{array}{l}\text { Generators oversized to supply } \\
\text { load from single generator } \\
\text { Inverter and motor fault current } \\
\text { tolerance overrated }\end{array}$ & $\begin{array}{l}\text { ESS on ring bus bar for short } \\
\text { term supply to motor via } \\
\text { converter }\end{array}$ \\
\hline \multirow[t]{2}{*}{$\begin{array}{l}\text { Non- } \\
\text { critical }\end{array}$} & $\begin{array}{l}\text { De-energise Faulted } \\
\text { Network }\end{array}$ & $\begin{array}{l}\text { AC breakers and converter } \\
\text { switching capability }\end{array}$ & $\mathrm{AC} \& \mathrm{DC} \mathrm{SSCBS}$ & $\begin{array}{l}\text { Co-ordinated operation of } \mathrm{AC} \\
\text { breakers and/ or Z-source } \\
\text { breakers }\end{array}$ \\
\hline & $\begin{array}{l}\text { Physically Isolate Faulted } \\
\text { Network to Prevent Fault } \\
\text { Propagation }\end{array}$ & $\begin{array}{l}\text { AC breakers at machine side } \\
\text { DC switches isolate after } \\
\text { operation of AC switches }\end{array}$ & $\begin{array}{l}\text { Open DC switches after SSCBs } \\
\text { have operated }\end{array}$ & $\begin{array}{l}\text { Open mechanical contactor in } \\
\text { Z-source breaker } \\
\text { AC EMCBs }\end{array}$ \\
\hline
\end{tabular}

\section{H. Reiteration process}

As new technologies emerge or standards become better defined, the design process can be repeated. Design decisions and outcomes from defining the FMS, architecture and detailed FM design can be fed back and the PLRs can then be adjusted to widen or narrow the selection of feasible solutions. Numerous iterations would also establish the impact of a bias towards a particular architecture, particularly if this may cause other potential solutions to be overlooked [31]. Acknowledging the assumptions for each design iteration is also useful in terms of planning and optimizing future design cycles. This would allow alternative assumptions to be chosen and the process repeated.

\section{CONCLUSIONS}

In conclusion, this paper has shown that an effective methodology for the design of FM orientated electrical architectures for future EPA is required. The development of FM technologies which can form effective FMSs is a priority and must be conducted in parallel with the development of the other systems and components for EPA. Retrospectively scoping the viable FM options or selecting an appendage FM solution which is not fully incorporated into the wider design is liable to be infeasible due to a small number of electrical technologies available from which to compile any solution.

The identification of the goal of the FM system under faulted conditions is a vital stage in the framework that has not yet been considered in depth in the published literature for an EPA electrical architecture. This goes beyond the specification of individual FM technologies towards identifying FM solutions which combine the available FM functionality of both components and the architecture itself, in order to perform a desired fault response. The system goal will drive the required FM functions and choice of technologies and therefore is critical to ensuring that only devices that are proven as necessary to the wider system design are actually included in the FMS. This framework has also clearly indicated the impact of the assumptions on the choice of FMS. The basic assumption underpinning many of the proposed architectures in the literature 
(that the desired electrical FM technologies would actually be available) has been addressed in the way that this proposed methodology eliminates infeasible solutions early on in the design process.

The interdependency between the electrical architecture (and hence the FM) and the aircraft conceptual design has been demonstrated in this paper. It is clear that the electrical architecture cannot be designed in isolation from the airframe and other aspects of the conceptual design.

This paper has also shown that there is an opportunity to innovate in the approach taken to the electrical architecture design. Electrical architectures which would not be considered under other metrics or for other applications may in fact be a useful route of development, given the unique range of challenges which are associated with the design of future electrical propulsion aircraft.

\section{FUTURE WORK}

It is notable from the framework case study that none of the FMS solutions for a 2035 EIS are "High" confidence, and there is only a single FM device which is considered to be "High" confidence. Therefore, there is further work to be done to develop the relevant FM technologies so that there is an array of technologies at high confidence level from which to compile a robust FMS. The process of heat mapping has also demonstrated the difficulty in monitoring and estimating technology development, particularly where there is a lack of published data. Hence, this activity would benefit from collaboration within the industry and publication of any state-of-the-art developments in FM devices and system overrating concepts.

Throughout this paper the authors have argued that fault management needs to be considered from a systems level perspective, and must consider the electrical fault management devices together in a strategy and not as individual technologies. Therefore, developmental road maps and targets for potential fault management strategies (incorporating aspects of systems overrating and the capability of the individual devices) are required. This will focus research efforts and identify any fault management strategies which may be challenging to implement within a given developmental timeframe.

As EPA currently require significant development before becoming commercially available, aircraft demonstrators in the interim period will be necessary to test the integration of systems and prove key technologies. These demonstrators will also need to integrate fault management from the outset of the design process and will need to demonstrate the viability of the fault management strategy which has been adopted. Further study of effective methodologies to integrate FM into the design of these test demonstrators is necessary. This will enable identification of the demonstrator specific requirements and technology constraints that will shape the viable electrical architectures for these demonstrators, especially where they are at a systems level or larger scale and therefore limited in the choice of available fault management technologies.

\section{ACKNOWLEDGEMENT}

This work was carried out as part of the Rolls-Royce University Technology Centre program at the University of Strathclyde. 


\section{REFERENCES}

[1] European Commission, Flightpath 2050, Europe's Vision for Aviation. Luxembourg, 2011.

[2] H. D. Kim, G. V. Brown, and J. L. Felder, "Distributed Turboelectric Propulsion for Hybrid Wing Body Aircraft," 2008 Int. Powered Lift Conf., pp. 1-11, 2008.

[3] Aerospace Technology Institute, "Electrical Power Systems," 2018. [Online]. Available: https://www.ati.org.uk/resource/insight_07-electricalpower-systems/.

[4] Robert Thomson (Roland Berger), Maxim Nazukin, Nikhil Sachdeva, Nicolas Martinez, "Aircraft Electrical Propulsion - The Next Chapter of Aviation?," 2017.

[5] M. K. Bradley and C. K. Droney, "Subsonic Ultra Green Aircraft Research: Phase II - Volume II - Hybrid Electric Design Exploration,” California, 2015

[6] A. R. Gibson et al., "The Potential and Challenge of TurboElectric Propulsion for Subsonic Transport Aircraft," in 48th AIAA Aerospace Sciences Meeting Including the New Horizons Forum and Aerospace Exposition, 2010, pp. 2010-276.

M. J. Armstrong et al., “Architecture, Voltage, and Components for a Turboelectric Distributed Propulsion Electric Grid (AVC-TeDP),” 2015. [Online]. Available: http://ntrs.nasa.gov/archive/nasa/casi.ntrs.nasa.gov/20150014237.pdf. [Accessed: 16-Sep-2016].

[8] K. J. Karimi, "Future Aircraft Power Systems-Integration Challenges,” The Boeing Company, 2007. [Online]. Available: https://www.ece.cmu.edu/ electriconf/2008/PDFs/Karimi.pdf. [Accessed: 18-Apr-2018].

[9] P. Gemin, T. Kupiszewski, A. Radun, Y. Pan, and R. Lai, “Architecture, Voltage and Components for a Turboelectric Distributed Propulsion Electric Grid (AVC-TeDP),” 2015. [Online]. Available: https://ntrs.nasa.gov/archive/nasa/casi.ntrs.nasa.gov/20150014583.pdf.

[10] M.-C. Flynn, C. Jones, P. Norman, and S. Galloway, "Fault Management Strategies and Architecture Design for Turboelectric Distributed Propulsion,” in Electrical Systems for Aircraft, Railway, Ship Propulsion and Road Vehicles, 2016.

[11] S. Clarke, M. Redifer, K. Papathakis, A. Samuel, and T. Foster, "X-57 power and command system design," in 2017 IEEE Transportation Electrification Conference and Expo (ITEC), 2017, pp. 393-400.

[12] R. H. Jansen, C. Bowman, and A. Jankovsky, "Sizing Power Components of an Electrically Driven Tail Cone Thruster and a Range Extender," in 16th AIAA Aviation Technology, Integration, and Operations Conference, AIAA AVIATION Forum, 2016, pp. 2016-3766.

[13] F. Anton, "HYPSTAIR - System Architecture, Certifiability and Safety Aspects," in E2 Fliegen Symposium, 2017.

[14] Heintje Wyczisk and Claus Zeumer, "HYPSTAIR - System Architecture, Certifiability and Safety Aspects Symposium E2-Fliegen 2016, Stuttgart," in Symposium E2-Fliegen 2016, 2016.

[15] P. Malkin, "Electric Power Systems for MEA and the Link to Hybrid Electric," in More Electric Aircraft Conference - Hybrid-Electric Aircraft Technology, 2016.

[16] N. E. Antoine and I. M. Kroo, "Framework for Aircraft Conceptual Design and Environmental Performance Studies," AIAA J., vol. 43, no. 10, pp. $2100-2109,2005$

[21] S. Stückl, A. Mirzoyan, and A. T. Isikveren, "DisPURSAL D1.2 - Report on the Technology Roadmap for 2035,” 2015.

[22] J. L. Felder, G. V Brown, H. D. Kim, and J. Chu, "Turboelectric Distributed Propulsion in a Hybrid Wing Body Aircraft," in International Society of Air Breathing Engines, 2011.

[23] B. Schiltgen, A. R. Gibson, M. Green, and J. Freeman, "More Electric Aircraft: 'Tube and Wing' Hybrid Electric Distributed Propulsion with 
Superconducting and Conventional Electric Machines," SAE Tech. Pap., vol. 2013-01-23, 2013.

[24] EASA, “AMC-20 Amendment 7 - Annex II AMC 20-6 rev. 2,” 2010. [Online]. Available: https://www.easa.europa.eu/system/files/dfu/Annex II AMC 20-6.pdf. [Accessed: 10-Apr-2017].

[25] S. Fletcher, P. Norman, S. Galloway, and G. Burt, "Fault detection and location in DC systems from initial di/dt measurement," in Paper presented at Euro Tech Con Conference, Manchester, United Kingdom., 2012.

[26] M.-C. Flynn, C. Jones, P. Rakhra, P. Norman, and S. Galloway, "Impact of key design constraints on fault management strategies for distributed electrical propulsion aircraft," in AIAA Energy and Propulsion Conference, 2017. NASA, “TRL Definition Hardware Description Software Description Exit Criteria,” 2015. [Online]. Available: https://ocw.mit.edu/courses/aeronautics-and-astronautics/16-522-space-propulsion-spring-2015/assignments/MIT16_522S15_TRLDefinition.pdf. [Accessed: 09-May-2018]. B. Sauser, D. Verma, J. Ramirez-Marquez, and R. Gove, "From TRL to SRL: The concept of systems readiness levels," Conf. Syst. Eng. Res. Los Angeles, CA, pp. 1-10, 2006

[29] S. Fletcher, M. Flynn, C. E. Jones, and P. J. Norman, "Hybrid Electric Aircraft: State of the Art and Key Electrical System Challenges," Transp. Electrif. eNewsletter, no. September, 2016.

[30] L. Mackey, M. R. K. Rachi, C. Peng, and I. Husain, “Optimization of a Z-source, ultra-fast mechanically switched, high efficiency DC circuit breaker," in 2017 IEEE Energy Conversion Congress and Exposition (ECCE), 2017, pp. 3764-3770.

[31] R. F. Beach, "Overview of NASA Power Technologies for Space and Aero Applications," in IEEE Cleveland Power and Energy Society Met, 2014.

[32] J. S. Gray, C. A. Mader, G. K. Kenway, and J. Martins, “Approach to Modeling Boundary Layer Ingestion using a Fully Coupled PropulsionRANS Model," in 58th AIAA/ASCE/AHS/ASC Structures, Structural Dynamics, and Materials Conference, 2017. 